\title{
O CUIDAdo DA CRIANÇA SEgundo TRABALhAdoras DE CRECHES ${ }^{1}$
}

\author{
Maria De La Ó Ramallo Veríssimo \\ Rosa Maria Godoy Serpa da Fonseca ${ }^{3}$
}

Veríssimo MDLOR, Fonseca RMGS. O cuidado da criança segundo trabalhadoras de creches. Rev Latino-am Enfermagem 2003 janeiro-fevereiro; 11(1):28-35.

Esta investigação objetivou apreender e analisar as representações de trabalhadoras de creches acerca do cuidado da criança. Os dados foram coletados em creches de uma universidade pública, no Município de São Paulo, Brasil, mediante entrevistas individuais e uma oficina pedagógica. Aqui é apresentado o tema O cuidado da criança na creche, parte dos resultados do estudo. O cuidado foi definido como atendimento às necessidades físicas e emocionais infantis, como etapa preliminar às atividades pedagógicas e como momento de aprendizado para as crianças. As trabalhadoras entendem o cuidado como fenômeno que prescinde de capacitação e habilitação específica e secundário em relação à educação. Atribuise essa compreensão de senso comum à falta de reflexão sobre um referencial teórico-conceitual que sustente a ação cuidadora das trabalhadoras.

DESCRITORES: creches, cuidado da criança, educação infantil, bem-estar da criança

\section{CHILDCARE ACCORDING TO DAYCARE CENTER WORKERS}

This investigation aimed at understanding and analyzing the representations of the workers from daycare centers regarding the care they provide to children. Data were collected through individual interviews and an educational workshop. These interviews were carried out in daycare centers, that are associated to a public university in the municipality of São Paulo, Brazil. The topic presented here, Childcare in daycare centers, is the first result of this study. The care was defined as actions taken to attend to the child's physical and emotional necessities, a preliminary step to pedagogical activities and as a learning moment for children. The workers understand the care as a phenomenon that do not need specific training or preparation as it is secondary if compared to education. This common sense understanding can be a result of the lack of reflection about a theoretical and conceptual reference that must base the performance of these workers.

DESCRIPTORS: child daycare centers, child care, child education, child welfare

\section{EL CUIDADO DEL NIÑO SEGÚN TRABAJADORAS DE JARDINES INFANTILES}

Esta investigación tubo el objetivo de conocer y analizar las representaciones de trabajadoras de jardines infantiles, con respecto al cuidado del niño. Los datos fueron obtenidos entre las trabajadoras de guarderías de una universidad pública del municipio de São Paulo, Brasil, por medio de entrevistas y de un taller pedagógico. Se presenta aquí el tema El cuidado del niño, como parte de los resultados de la investigación. Se verificó que las trabajadoras entienden el cuidado como todo lo que hacen para atender las necesidades infantiles, como un intermediario para el rol educativo, que consideran que sea el rol principal de la guardería, y como una actividad que no necesita de capacitación o habilitación específica, y que es, por su naturaleza, ejecutado por mujeres. Esta comprensión de sentido común es resultado de la falta de una base teórica y conceptual para dar sustentación a la acción cuidadora de las trabajadoras.

DESCRIPTORES: jardines infantiles, cuidado del niño, educación infantil, bienestar del niño

\footnotetext{
${ }^{1}$ Este trabalho é parte da Tese de Doutorado apresentada em agosto de 2001 ao Programa de Pós-Graduação, nível Doutorado, da Escola de Enfermagem da Universidade de São Paulo; ${ }^{2}$ Enfermeira, Professor Doutor, e-mail: mdlorver@usp.br; ${ }^{3}$ Enfermeira, Professor Titular. Escola de Enfermagem da Universidade de São Paulo
} 
INTRODUÇÃO

As creches surgiram no Brasil no século XIX, num contexto em que as instituições asilares eram a referência para entidades de atendimento à população e tinham como objetivo "livrar bebês e crianças pequenas da morte, através de fornecimento de abrigo, alimentação e algum atendimento em higiene e saúde, pois entendia-se que suas famílias de trabalhadores não podiam proporcionarIhes esses cuidados básicos" ${ }^{\text {(1). }}$.

Nesse mesmo período, também desenvolveu-se o setor privado da educação pré-escolar, voltado para as elites: os "jardins de infância" que foram propagandeados como tendo causas "essencialmente distintas" das creches destinadas às classes populares, pois atribuíase a eles um caráter "pedagógico"(2).

Em nosso meio, ainda estão presentes resquícios desses significados conferidos às creches em sua gênese. Ao mesmo tempo, frente às mudanças ocorridas nas organizações social e familiar, essas tornaram-se importante local onde as crianças crescem e se desenvolvem e vêm sendo requisitadas cada vez mais pela população.

Uma questão ainda em debate em nosso país é a definição e clareza da missão específica da creche, que oscilou de puramente assistencialista em sua origem, a educativa nos dias atuais.

Às creches assistencialistas atribuía-se o compromisso único de compensar aquilo que faltava à criança em sua casa, ainda que com baixa qualidade, pois os objetivos da educação assistencialista eram isolar as crianças dos meios perniciosos, como a rua, e oferecer educação de baixa qualidade, já que as crianças pobres "deveriam ser preparadas para o futuro que lhes era destinado, de maneira resignada, a uma posição social de submissão", não perdendo de vista o meio em que teriam que viver ${ }^{(2)}$.

Atualmente, esse modelo assistencialista tem sido muito criticado e combatido, mediante ênfase na missão educativa da creche. Sob a justificativa de que a missão da creche ou pré-escola é educar, muitas instituições têm organizado sua programação em torno de atividades pedagógicas exclusivamente, dando tarefas para a casa e afirmando que lugar de brincar é em casa e não na escola. Nesse caminho, tem-se negligenciado também um aprofundamento sobre o cuidado.

A dicotomia que tem marcado os projetos para o atendimento infantil em nosso país foi explicitada pelo Ministro da Educação, Paulo Renato de Souza, no Referencial Curricular Nacional para a Educação Infantil, publicado em 1998, quando afirmou que o documento "representa um avanço na educação infantil ao buscar soluções educativas para a superação, de um lado, da tradição assistencialista das creches e, de outro, da marca da antecipação da escolaridade das préescolas"(3).

Não é difícil perceber que, ao rejeitarem uma ou outra função da creche, ambas as visões terminam por incorrer num reducionismo que culmina na atenção parcializada à criança. Assim, considerar cuidado e educação como pilares intrinsecamente ligados na atenção à criança na creche e na pré-escola* , conforme preconiza o Referencial, é o desafio atual dessas instituições. Isso porque, na prática do atendimento nas creches observase uma visão de menosprezo ao cuidado e uma valorização do aspecto educativo, o que dá origem à idéia de que 0 cuidado pode estar sendo negligenciado ou realizado às custas de insatisfação das trabalhadoras. Nesse caso, depreende-se que, para alcançar a integração das ações de cuidado e educação, é preciso debater o que se compreende por cuidado à criança.

\section{OBJETIVO}

O objetivo deste trabalho foi apreender e analisar as representações das trabalhadoras que atuam em creches acerca do cuidado à criança, visando contribuir para o debate das diretrizes curriculares para a educação infantil e para a melhoria da atenção à criança que freqüenta creche.

\section{METODOLOGIA}

O estudo foi realizado junto a três creches de uma Universidade Pública, situadas no município de São Paulo. Os sujeitos do estudo foram nove educadoras, que são as trabalhadoras que atuam diretamente junto às crianças,

\footnotetext{
* A Lei de Diretrizes e Bases da Educação Nacional determina como primeira etapa da educação básica a educação infantil oferecida em creches, ou entidades equivalentes, para crianças de até três anos de idade e em pré-escolas, para as crianças de quatro a seis anos de idade. As instituições participantes desta investigação atendem crianças de 0 a 6 anos e são denominadas creches, razão pela qual utilizamos esse termo no trabalho
} 
e sete coordenadoras, que são profissionais de nível superior que compõem as equipes técnicas desses serviços e coordenam o trabalho nas creches.

O referencial teórico-metodológico adotado para a investigação foi a Teoria das Representações Sociais, de Serge Moscovici. Em função do grande volume do produto da análise dos dados, selecionou-se para apresentação neste artigo apenas os resultados que expressam os significados sobre o tema cuidado, obtidos pela análise temática de conteúdo.

Para a coleta de dados junto às coordenadoras, foram realizadas entrevistas semi-estruturadas e, para o grupo de educadoras, optou-se pela realização de uma oficina educativa, um tipo de técnica projetiva, grupal e associada à verbalização.

As entrevistas ocorreram no local de trabalho das participantes, a partir das seguintes questões: Para você, qual é a função da creche? Quais as vantagens e as desvantagens da criança freqüentar a creche? O que é cuidar? Qual a relação entre cuidar e educar? Relate uma situação que você considera que representa um bom cuidado para a criança e uma situação que você considera que representa que uma criança não foi bem cuidada. $O$ que significa cuidar da criança de outra pessoa? No decorrer das entrevistas, foram sendo elaboradas outras perguntas para esclarecer e aprofundar a compreensão acerca do que estava sendo exposto.

A oficina foi estruturada em quatro encontros, que tiveram como temas: o trabalho realizado no dia-a-dia; facilidades, dificuldades e sentimentos relativos ao cuidado; o enfrentamento das dificuldades e perspectivas: a reinvenção do cuidado da criança na creche.

As entrevistas e os encontros foram gravados e transcritos na íntegra. Os dados foram submetidos à análise temática de conteúdo, que "consiste em descobrir os núcleos de sentido que compõem uma comunicação cuja presença ou freqüência signifiquem alguma coisa para o objetivo analítico visado"(4). Ao final da análise, foram obtidos quatro temas: $\mathrm{A}$ creche, $\mathrm{O}$ trabalho na creche, $\mathrm{O}$ cuidado da criança na creche e A creche e a família. Neste texto, será apresentada a análise e discussão do tema o cuidado da criança na creche.

O projeto foi apreciado por um Comitê de Ética e as trabalhadoras foram esclarecidas acerca do objetivo e finalidade do trabalho, forma de coleta dos dados e de apresentação do relatório, garantindo-se o anonimato das informações. A todas que se interessaram em participar foi entregue um formulário de consentimento livre e esclarecido, para sua concordância formal. Foi garantida liberdade para integrar o grupo de participantes bem como de deixar o estudo em qualquer momento. Foi também afirmada a disponibilidade da pesquisadora para prestar esclarecimentos sobre o estudo, sempre que solicitados.

\section{RESULTADOS E DISCUSSÃO}

\section{Caracterização das coordenadoras}

As idades das sete coordenadoras variavam entre 29 e 56 anos, sendo a média 41 e a mediana 40 anos. Três delas tinham formação em psicologia, duas em pedagogia, uma em enfermagem e apenas uma ainda cursava pedagogia, tendo feito magistério. O tempo de trabalho na creche variou de 4 a 19 anos e o tempo de atuação em educação infantil de 4 a 24 anos. Apenas uma delas não teve experiência anterior com educação infantil. As demais tiveram experiências em outras creches ou "escolinhas" (3), escolas (2), escolas para crianças com necessidades especiais (2), Febem (1).

Caracterização das educadoras

A idade das nove educadoras variou de 23 a 42 anos, sendo a média em torno de 32 anos e a mediana 31 anos. Três dessas tinham formação de II Grau completo, modalidade magistério, 4 curso superior completo (pedagogia, psicologia e sociologia) e duas curso superior de pedagogia incompleto. O tempo de trabalho nas creches do estudo variou de 2 a 10 anos, sendo que apenas duas tinham menos de 4 anos e as demais (7) acima de 5 anos de vínculo. Quanto à experiência de trabalho anterior em outras creches, seis educadoras a tiveram. As demais (3) atuaram somente nas creches da universidade. Três delas tiveram experiências anteriores em outras atividades.

O cuidado da criança na creche

O tema o cuidado da criança na creche foi composto a partir dos subtemas: o cuidado da criança, o cuidado e o trabalho com a criança e relações entre cuidar e educar. A apresentação de cada um dos subtemas será feita em separado para os dois grupos: o de coordenadoras e o de educadoras. 
O cuidado da criança segundo as coordenadoras

Para as coordenadoras, cuidar é atender as necessidades da criança, para promover seu bem-estar físico e provê-la de relações afetivas e sociais. As necessidades mais citadas foram: alimentar, higienizar, agasalhar, cuidar do preparo do alimento, ensinar a comer, hidratar, deixar confortável, proporcionar segurança e bemestar físico. Atender as necessidades é "fazer", "ensinar", "supervisionar" a criança e deixar o ambiente confortável e seguro.

Foi apontado que a concepção atualizada sobre cuidado é toda intervenção que o adulto dirige à criança com a preocupação de transmitir conhecimentos, zelar por seu bem-estar e pela relação interpessoal, não restrita a ações pontuais para atender uma necessidade. Isso significa que os procedimentos não devem ser mecânicos, como se estivessem sendo realizados na criança; ao invés disso, as ações devem ser realizadas com a criança, o que demanda relacionamento e resulta em aprendizagem para ela.

Nessa visão, cuidar também é proporcionar atenção e liberdade. Atenção é olhar para, ouvir e conversar, colocando-se na altura da criança, o que denota respeito por ela. Liberdade é permitir que a criança desfrute o espaço da creche, explorando e brincando. Para isso, 0 cuidado contempla a organização do ambiente, de forma a permitir que a criança brinque e tenha oportunidades de desenvolver seu potencial, sendo sempre respeitada em seu ritmo individual.

Também foi definido que cuidar bem é acolher a criança apesar das diferenças que ela possa ter em relação a um padrão infantil idealizado, o que se refere especialmente às crianças com necessidades especiais. Nesse caso, cuidado é toda ação que visa garantir apoio e favorecer que a criança possa adquirir o máximo de competências.

A maioria das coordenadoras expressou que cuidar demanda criação de vínculo, isto é, estabelecer uma relação afetiva entre a educadora e a criança.

O Referencial Curricular expressa que o vínculo é necessário e conseqüência de algo anterior compromisso, solidariedade e confiança: "Para cuidar, é preciso antes de tudo estar comprometido com o outro, com sua singularidade, ser solidário com suas necessidades, confiando em suas capacidades. Disso depende a construção de um vínculo entre quem cuida e quem é cuidado"(3).

Afirmar que, para cuidar, é necessário ser afetivo, demanda uma reflexão acerca da afetividade numa relação profissional, evitando o senso comum de que basta gostar das crianças para cuidar bem delas. Além disso, pensar que todas as educadoras vinculam-se igualmente a todas as crianças e vice-versa, provavelmente, não condiz com a realidade.

Um exemplo do que ocorre nas creches em questão é esclarecedor da afirmação acima. É evidente que, quando a criança começa a freqüentar a creche, não é possível já haver vínculo. Mas a criança pode ser bem cuidada mesmo antes de entrar na creche, mediante a realização de atividades que visam preparar sua adaptação. Isso mostra que o adulto não depende do vínculo para cuidar bem, mas que ele está "pré-disposto" a cuidar e, de fato, o faz. Algumas hipóteses a respeito dos fundamentos do cuidado nesse período são: a internalização de atitude de respeito à criança e respeito à família, conhecimento das necessidades da criança (antítese do senso comum) e senso de dever, sendo nulo o poder explicativo do vínculo para o cuidado nessa fase.

Outro enfoque sobre a afetividade foi o de que o adulto precisa estar atento à criança. Estar atento corresponde à primeira etapa do cuidado - "o conhecimento" - considerando que "o cuidador deve ser capaz de entender as necessidades do outro e de responder a elas de forma

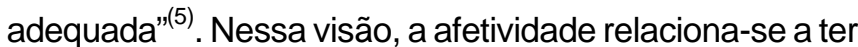
sensibilidade para perceber o que a criança precisa, pois, para atender as necessidades, é preciso saber reconhecêlas e como atendê-las.

É preciso também compreender as características particulares da cultura na qual as crianças estão inseridas. Isso implica a necessidade de contato aprofundado com a família, o que, além de permitir o conhecimento dos valores, saberes, atitudes educativas, também possibilita o conhecimento de suas expectativas, medos e necessidades em relação à creche.

O cuidado foi explicado ainda como uma atitude de atenção individualizada, respeito às dificuldades e ajuda, presente inclusive no processo educativo formal. Essa é a perspectiva de que "cuidar é ajudar o outro a crescer e a se realizar, num processo de desenvolvimento, em que o outro ser humano é respeitado como ser independente, assim como são respeitadas suas necessidades, cujo atendimento é compromisso do cuidador"(5).

O cuidado da criança segundo as educadoras

Para as educadoras, o cuidado refere-se ao 
atendimento das necessidades da criança para prover seu bem-estar e a atenção para com ela. Verificou-se que as necessidades consideradas são a higiene, a alimentação e a segurança. Por isso, afirmam que as crianças pequenas demandam mais cuidado que as maiores, embora destaquem que a responsabilidade de garantir a segurança física demanda cuidados para com todas as crianças.

A percepção da responsabilidade pela segurança reitera a concepção do cuidado como função da educadora. Essa idéia concorda com a afirmação "A polarização entre assistencial e educacional opõe a função de guarda e proteção à função educativa, como se ambas fossem incompatíveis, uma excluindo a outra. Entretanto, a observação das instituições escolares evidencia que elas têm como elemento intrínseco ao seu funcionamento a guarda das crianças que as freqüentam: "As instituições educacionais, especialmente aquelas para a pequena infância, apresentam-se à sociedade e às famílias de qualquer classe social como responsáveis pelas crianças no período que as atendem"(2) .

Foi enfatizado que o cuidado na creche é diferente do cuidado em casa porque é um cuidado profissional, fundamentado em princípios científicos e rotinas institucionais e também porque a relação com as crianças na creche é diferente da relação com os próprios filhos, pois afirmam que "ser mãe é diferente de ser educadora".

Quando a realização dos cuidados ou as interações com as crianças apresentam-se difíceis, as educadoras vivenciam sentimentos que as mobilizam para a busca de respostas. As situações mais corriqueiras são a recusa da criança em ficar na creche no horário da chegada, a recusa em alimentar-se e o choro. Os depoimentos explicitam que há necessidade de aprofundar o que seja o cuidado. Mostram internalização de responsabilidade, mas também um sentimento de angústia com as recusas da criança e um certo desconhecimento sobre como cuidar nesses momentos, contrariando os discursos das coordenadoras e das próprias educadoras que a forma de lidar com essas situações na creche é diferente da maneira como as mães lidam, pois é "profissional".

O cuidado e o trabalho com as crianças segundo as coordenadoras

Para as coordenadoras, o cuidado é imperativo, inserindo-se no trabalho porque há uma demanda da criança por cuidado que não pode ser negligenciada. $O$ fato da criança não ser ainda capaz de satisfazer, por si própria, suas demandas implica a existência de um provedor.

O atendimento da criança na creche demanda, então, o oferecimento de ações que não constituem atividades pedagógicas, mas que são essenciais à criança. Para tanto, é preciso contar com profissionais capacitadas com conhecimentos e habilidades específicos tais como a capacidade de observar, interpretar e compreender os comportamentos e necessidades infantis.

Todas as coordenadoras, entretanto, destacam que os cursos da área de educação não preparam os profissionais adequadamente para esse trabalho, especialmente no que se refere às crianças menores de 3 anos. Esse conhecimento é adquirido, dessa forma, no próprio contato com o trabalho na creche, tal como evidenciado em outros estudos ${ }^{(6)}$.

Por isso, as educadoras reproduzem no cuidado aquilo que aprenderam desde sua infância, segundo uma visão leiga, de senso comum, e o trabalho com crianças pequenas é sentido como sendo de menor valor em termos do que seja o trabalho profissional do educador.

Essa concepção evidencia-se em muitos serviços de creche em nosso país, nos quais há uma divisão das atividades: as auxiliares das professoras realizam as ações de higiene, alimentação, repouso, enquanto as professoras somente realizam atividades de "sala de aula", pedagógicas. Isso não ocorre nas creches deste estudo, pois todas as atividades realizadas com as crianças são de responsabilidade direta das educadoras.

Nesse cenário, depreende-se que a inserção do cuidado no trabalho com a criança tende a caracterizarse como tarefa para a qual as educadoras nem sempre vêem sentido nas ações realizadas por elas, pois essa tarefa é concebida como pólo oposto à educação, particularmente quando ingressam no serviço. Apesar da falta de preparo e de valorização para o cuidado ter sido atribuída a deficiências dos cursos, pode-se aventar como razão que nossa cultura não valoriza o cuidado. Por isso, mesmo com todo o trabalho das equipes técnicas, é difícil transformar a visão das educadoras de forma radical.

Um aspecto do trabalho com as crianças menores, que as coordenadoras identificam como frustrante para as educadoras, é a ausência de produto visível, mensurável. A criança pequena não tem uma produção que represente a influência da educadora, tal como a confecção de trabalhos manuais, ou que demonstre um aprendizado proporcionado por ela, mediante o 
desenvolvimento da leitura, da escrita ou da matemática. Isso pode lhes causar angústia, particularmente quando comparam os resultados e aquisições das suas crianças com as maiores.

Essa perspectiva da falta de produto pedagógico sugere que a medida para avaliar o trabalho é aquela importada do ensino fundamental tradicional, centrada no ensino de competências para a realização de tarefas acadêmicas. Sugere, ainda, que não se construiu um rol de resultados específicos esperados para a educação infantil. Assim, embora a equipe da creche realize uma série de cuidados efetivos para o bem-estar das crianças, que promovem seu desenvolvimento e aprendizagem, a ausência de um quadro conceitual que ampare e sustente esse cuidado não permite que ele seja visto, sistematizado, avaliado e computado como produto de um trabalho profissional.

Alguns exemplos de produtos relativos ao trabalho com crianças pequenas que podem ser avaliados são: em que medida a criança está livre de infecções, dormindo, alimentando-se e/ou mantendo rotinas estáveis; o quanto ela brinca, explora, pergunta, busca ajuda quando precisa, demonstrando confiança em si e nos educadores; o quanto os adultos estão realizando cuidados de modo sistematizado; quanto a família está tranqüila e informada a respeito da vida da criança na creche.

É correto, entretanto, afirmar que, na história da creche, muitos desses aspectos nunca foram sistematizados. Exemplificando, a proposta higienista deveria visar, minimamente, o produto "o quanto a criança está livre de infecções", mas o que se observa é um grande paradoxo: programas que escolhem ou priorizam os aspectos de cuidado e, contudo, apresentam resultados alarmantes em relação ao cuidado infantil, que resultam, em geral, em epidemias crônicas. Exemplos de problemas corriqueiros são: equipamentos sujos, crianças confinadas, tanques de areia vazios e/ou maltratados, iluminação e acústica inadequadas, precária higiene pessoal dos adultos e crianças, maus odores acentuados, falta de material de limpeza e conservação ${ }^{(7-8)}$.

Assim, embora as creches universitárias apresentem resultados bastante satisfatórios, no que diz respeito aos cuidados citados, esses resultados não são reconhecidos pelo grupo de educadoras como fruto de sua função profissional.

O cuidado e o trabalho com as crianças segundo as educadoras

Para as educadoras, o cuidado também é imperativo. Embora enfatizado como algo necessário e imprescindível, foi descrito como um momento separado, exclusivo, e uma etapa preparatória para o momento educativo.

Notou-se que os sentimentos das educadoras quanto ao cuidado oscilam, pois elas também são influenciadas pelas representações de cuidado como atividade que não demanda uma base de conhecimento e de cuidado infantil como pertencente ao âmbito da família.

Em relação ao primeiro ponto, presume-se que essa visão decorra de que o cuidado com o corpo da criança implica um trabalho manual, que vem sendo realizado em toda história da humanidade como atividade simplesmente prática, segundo bases empíricas, tendo, portanto, menor valor social.

Quando se diz que não é necessário curso superior para fazer higiene, trocar fraldas, dar banho na criança, isso pode ser válido para o ambiente doméstico, mas não o é para o espaço coletivo. Nesse, "a simples higiene tem que ser feita com competência, pois, do contrário, tornase um risco à saúde das crianças e dos trabalhadores. Isso implica em compreender processos de contaminação pessoal e ambiental e que o desenvolvimento da criança também está sendo influenciado, seja na formação de sua identidade seja na incorporação de valores relativos ao cuidado com o corpo, por exemplo"(9).

Quanto ao segundo ponto, a idéia de que a educadora confunde-se com a família quando cuida da criança decorre de que o cuidado infantil é tido como função materna. A sociedade moderna ocidental atribui à mulher a principal responsabilidade pela sobrevivência, saúde e educação do filho, e entende que ela foi dotada pela natureza de condições ideais para o cuidado infantil ${ }^{(10)}$. Tanto que, historicamente, o atendimento das crianças em creches tem sido feito predominantemente por leigos, em geral com precária instrução formal. Assim, não é de estranhar que as pessoas esperem que essas atividades sejam executadas por uma auxiliar (basta ser mulher) e que apenas as funções "mais nobres", as educativas, sejam da professora.

Aparece aí também uma concepção simplista sobre educação como "dar aulas" e, portanto, torna-se incompreensível, para os leigos, a função de uma professora junto a crianças pequenas. Essas concepções simplistas, de senso comum, tanto para o cuidado quanto para a educação, foram apresentadas como um problema pois estão presentes não só fora das creches, mas 
também nas próprias equipes, realidade que não é exclusiva do nosso país. Em geral, nas creches, "o educador é colocado frente à tarefa educativa, sem preparação específica nem em puericultura, nem em técnicas de intervenção didática, nem em conhecimento sobre o desenvolvimento, nem em dinâmicas relacionais entre adulto e criança e entre adultos"(11).

Relações entre cuidar e educar segundo as coordenadoras

As coordenadoras exploram a relação entre cuidar e educar de acordo com suas convicções acerca da função da creche, destacando-se como a relação mais citada a possibilidade de ensinar algo, de promover aspectos educativos, tais como aprender sobre as partes do corpo ou como se comportar à mesa durante as atividades de higiene e alimentação.

Ao explicarem o cuidado e falar de sua dificuldade em separá-lo da educação, expressam uma inter-relação íntima e indissociável entre ambos, umas englobando o cuidado na educação, outras a educação dentro do cuidado. Como ponto comum, afirmam que a integração ou separação entre cuidado e educação constrói-se na maneira de organizar o dia-a-dia da criança e nas relações que o educador cria com as atividades.

Tais idéias mostram-se condizentes com concepções mais atuais de desenvolvimento infantil que "situam a criança em seu contexto social, ambiental, cultural e, mais concretamente, no contexto das interações que estabelece com os adultos, crianças, espaços, coisas e seres à sua volta", e que afirmam "as diretrizes curriculares definem-se também de forma integrada, sem privilegiar um aspecto em detrimento do outro"(12).

Relações entre cuidar e educar segundo as educadoras

Todas as educadoras apontaram as atividades de cuidado como parte de seu papel, mas sentem-se frustradas, porque identificam que seu fazer não é reconhecido como educativo e as atividades relacionadas ao corpo da criança são discriminadas também por profissionais formados para atuar na área da educação, inclusive pelas trabalhadoras das creches do estudo. A exemplo, em resposta às manifestações de que o trabalho com as crianças pequenas é centrado na higiene, isto é, no cuidado, elas buscam identificar sinais que possam demonstrar que a dimensão pedagógica do processo educacional começa no berçário, dizendo que se as crianças gostam de ler quando chegam à pré-escola é graças ao estímulo que receberam quando estavam no berçário.
Para algumas, as atividades "de cuidado para o bem-estar" são separadas das "atividades pedagógicas", ocorrendo em momentos diferentes e sendo, as primeiras, uma condição necessária para o desenvolvimento das ações pedagógicas. Nesse caso, depreende-se um certo privilégio aos aspectos cognitivos, com organização de conteúdos por áreas de conhecimentos, tal como nas disciplinas escolares, não mencionando articulação entre ações de cuidado e função pedagógica. Essa forma de definir o trabalho junto à criança mostra dicotomia entre educação e cuidado, com maior valorização do pedagógico.

Não foram citados aspectos relativos à aprendizagem infantil e que constituem ações educativas e de cuidado tais como o movimento, o equilíbrio, o toque, o colo, a construção da identidade, as oportunidades para explorar, o estabelecimento de relações, a descoberta do próprio potencial, das próprias competências, a percepção de si como ser de valor, enfatizando-se o desenvolvimento de conhecimentos e comportamentos típicos da escolarização formal.

Apenas uma educadora relacionou as atividades de cuidado com o aspecto pedagógico, considerando que a criança aprende durante tais atividades e que essa é a concepção presente nas creches da universidade. Entretanto, ela foi contestada pelas demais que afirmaram não ser essa a visão unânime das educadoras, mesmo naquelas creches.

A despeito das divergências, o que há de comum nos discursos é a idéia de que a importância do cuidado se dá por relacionar-se à aprendizagem. Quer dizer, não se atribui um valor independente ao cuidado. O que pode justificar essa visão é que há uma lacuna na sistematização do cuidado, dificultando que ele possa ser objetivado, mediante planejamento, com definição de objetivos, estratégias e avaliação, considerando os aspectos específicos, sem atrelar sua importância ao aprendizado de algo.

\section{CONSIDERAÇÕES FINAIS}

Mesmo não tendo um corpo teórico-conceitual, o cuidado permeia o cotidiano da instituição do estudo. É possível afirmar que existe atitude de cuidado, embora ela não esteja consciente. Conhecendo as necessidades das crianças, podemos avaliar que as conseqüências desse "pólo", mesmo pouco desenvolvido, são de uma qualidade que se destaca no panorama brasileiro. Portanto, 
é estimulante pensar sobre o que poderia ser alcançado, caso a instituição se voltasse à formulação de um corpo conceitual do cuidado.

De acordo com o previsto na Lei de Diretrizes e Bases da Educação Nacional, e conforme tem sido norteada a coordenação das creches desta investigação, as creches têm como finalidade $\mathrm{o}$ atendimento em educação infantil, contemplando as necessidades de desenvolvimento intelectual e o acesso ao saber, bem como o direito à socialização, às vivências infantis e aos cuidados assistenciais específicos e necessários. Para atingir tal finalidade, repensar o significado das creches nas universidades públicas, centros produtores e disseminadores do saber científico, implica minimamente repensar o saber que deve nortear o desenvolvimento intelectual e a socialização.

Uma maneira de resignificar a posição do cuidado é entendê-lo abrangendo "um conjunto de conhecimentos teóricos e práticos, fundamentados numa base científica e humanística" ${ }^{(13)}$.

O objetivo de superar os enfoques que contrapõem cuidado e educação, almejando "metas de qualidade que contribuam para que as crianças tenham um desenvolvimento integral de suas identidades, capazes

\section{REFERÊNCIAS BIBLIOGRÁFICAS}

1. Merisse A. Origem das instituições de atendimento à criança: o caso das creches. In: Merisse A, Justo JS, Rocha LC da, Vasconcelos MS. Lugares da infância: reflexões sobre a história da criança na fábrica, creche e orfanato. São Paulo (SP): Arte Ciência; 1997. p.25-51

2. Kuhlmann M Jr. Instituições pré-escolares assistencialistas no Brasil (1899-1922). Cad Pesq 1991; 78:17-26.

3. Ministério da Educação e do Desporto (BR). Secretaria de Educação Fundamental. Referencial Curricular Nacional para a Educação Infantil. Brasília (DF); 1998.

4. Minayo MC de S. O desafio do conhecimento: pesquisa qualitativa em saúde. $2^{a}$ ed. São Paulo: HUCITEC-ABRASCO; 1993.

5. Mayeroff M. On caring. New York: Harper \& Row; 1971.

6. Barreto AMRF. Por que e para que uma política de formação do profissional de educação infantil? In: Ministério da Educação e do Desporto (BR). Secretaria de Educação Fundamental. Por uma política de formação do profissional de educação infantil. Brasília (DF): COEDI/MEC; 1994.

7. Demo P. Educação e qualidade. Campinas: Papirus; 1995. 8. Machado ML. Pré-escola é ou não é escola: a busca de um caminho. São Paulo: Paz e Terra; 1991.

9. Rosemberg F. Formação precária na pré-escola. [online]. [acessado em 14 de maio 2001]. Disponível em: <http:// www.sinpro-rs.org.br/extra/jun98/educa1.htm>. de crescerem como cidadãos, cujos direitos à infância

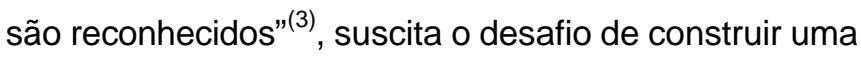
nova visão, um novo referencial de atendimento.

Para que a educadora se torne também um recurso de cuidado, é necessário um "novo tipo de formação, baseada numa concepção integrada de desenvolvimento e educação infantil, que não hierarquize atividades de cuidado e educação e não as segmente em espaços, horários e responsabilidades profissionais diferentes"(12).

Esse enfoque responde à finalidade de promover saúde à criança usuária do serviço, numa perspectiva de superar a noção de que a creche seja um "mal necessário", um risco ao desenvolvimento infantil. Entende creche como um direito da criança, como um espaço de vida e saúde, de interações, de descobertas e aprendizagem, de desenvolvimento das potencialidades e cidadania infantil.

É sob essa ótica que a enfermagem pode e deve contribuir para a atenção à criança na creche e na escola, não somente realizando intervenções pontuais de controle de saúde como também ajudando a construir um referencial que possibilite a atenção integral da criança em instituições de educação e a melhoria do processo de formação dos trabalhadores para essa área.

10. Badinter E. Um amor conquistado: o mito do amor materno. Rio de Janeiro: Nova Fronteira; 1985.

11. Bondioli A, Mantovani S. Manual de educação infantil: de 0 a 3 anos - uma abordagem reflexiva. 9. ed. Porto Alegre: Artes Médicas; 1998.

12. Campos MM. Educar e cuidar: questões sobre o perfil do profissional de educação infantil. In: Ministério da Educação e do Desporto (BR). Secretaria de Educação Fundamental. Por uma política de formação do profissional de educação infantil. Brasília: COEDI/MEC; 1994. p.32-42.

13. Boehs AE, Patrício ZM. O que é este "cuidar/cuidado": uma abordagem inicial. Rev Esc Enfermagem USP 1990; 24(1):111-6. 